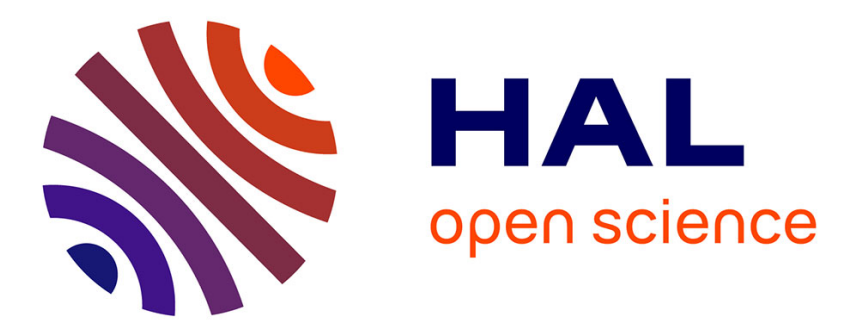

\title{
Prediction of BPF tones emitted by the inlet of an aero-engine model using in-duct angular mode spectrum measurements
}

G. Reboul, C. Polacsek, G. Billonnet, J.M. Roux

\section{- To cite this version:}

G. Reboul, C. Polacsek, G. Billonnet, J.M. Roux. Prediction of BPF tones emitted by the inlet of an aero-engine model using in-duct angular mode spectrum measurements. 20th AIAA/CEAS Aeroacoustics Conference, Jun 2014, ATLANTA, United States. hal-01067826

\section{HAL Id: hal-01067826 \\ https: / hal-onera.archives-ouvertes.fr/hal-01067826}

Submitted on 24 Sep 2014

HAL is a multi-disciplinary open access archive for the deposit and dissemination of scientific research documents, whether they are published or not. The documents may come from teaching and research institutions in France or abroad, or from public or private research centers.
L'archive ouverte pluridisciplinaire $\mathbf{H A L}$, est destinée au dépôt et à la diffusion de documents scientifiques de niveau recherche, publiés ou non, émanant des établissements d'enseignement et de recherche français ou étrangers, des laboratoires publics ou privés. 


\section{Prediction of BPF tones} emitted by the inlet of an aero-engine model using in-duct angular mode spectrum measurements.

G. Reboul, C. Polacsek, G. Billonnet, J.M. Roux *

20th AIAA/CEAS Aeroacoustics Conference ATLANTA, USA

16-20 juin 2014

\section{ONERA}

THE FRENCH AEROSPACE LAB 

Prediction of BPF tones emitted by the inlet of an aero-engine model using in-duct angular mode spectrum measurements.

\title{
Prévision du bruit tonal émis par l'entrée d'un turbofan en utlisant des mesures de modes angulaires.
}

\author{
par \\ G. Reboul, C. Polacsek, G. Billonnet, J.M. Roux * \\ * SNECMA Moteurs, Villaroche
}

\section{Résumé traduit :}

Le but de cette étude était de réaliser des prédictions de bruit tonal générées par une maquette de turboréacteur à double flux SNECMA avec un stator hétérogène et rayonnée à partir de l'entrée en utilisant comme données d'entrée une décomposition modale réalisées à la paroi du conduit d'admission. Une approche numérique basée sur la CAA (Computational AeroaAcoustic), code sAbrinA.Vo, avec un terme source équivalent récemment mis en place, ainsi qu'une méthode d'analytique utilisant une technique de Wiener- Hopf et une hypothèse d'écoulement uniforme, sont utilisées. Même si les directivités fournies par les données expérimentales brutes présentent d'importantes variations de niveau de bruit dans la direction azimutale prouvant que l'effet de corrélation entre les modes semble pas être négligeable, l'hypothèse de modes incohérents induisant des directivités de révolution permet d'obtenir un bon accord avec les données mesurées moyennées azimutalement. Les comparaisons entre les prédictions théoriques et numériques confirment l'intérêt pratique de l'utilisation de méthodes d'analytique simplifiées, même si une nette amélioration est fournie par des méthodes plus complexes et fastidieuses comme la CAA. Pour les angles situés entre $20^{\circ}$ et $70^{\circ}$, un très bon accord est obtenu avec un écart maximal de $0,7 \mathrm{~dB}$ sur le niveau global de pression acoustique pour les trois premières raies. 



\title{
Prediction of BPF tones emitted by the inlet of an aero-engine model using in-duct angular mode spectrum measurements
}

\author{
G. Reboul, C. Polacsek, G. Billonnet* \\ ONERA, BP 72, F92322, Châtillon Cedex, France \\ J.M. Roux ${ }^{\dagger}$ \\ SNECMA Villaroche (SAFRAN Group), 77550 Moissy Cramayel, France
}

\begin{abstract}
The goal of this study was to realize predictions of tonal noise generated by a SNECMA turbofan mock up with a heterogeneous stator and radiated from the inlet using as input a modal decomposition made in the inlet duct wall. A numerical approach based on the CAA (Computational AeroAcoustics) code $s A b r i n A$. VO with an equivalent source term recently implemented is used as well as an analytical methodology using a Wiener-Hopf technique and an uniform flow assumption. Even if directivities from raw experimental data exhibit significant variations of noise level in the azimuthal direction proving that correlation effect between modes seems to be not negligible for tonal noise, the hypothesis of incoherent modes inducing axisymmetric directivities allow to compare reasonably well with measured data averaged azimuthally. Comparisons between theoretical and numerical predictions confirm the practical interest of using simplified analytical methods even if clear improvement are provided by more complex and time consuming methods like CAA. Especially, for polar angles between $20^{\circ}$ and $70^{\circ}$, a very good agreement is obtained with a maximum discrepancy of $0.7 \mathrm{~dB}$ on overall sound pressure level for the three first tones.
\end{abstract}

\section{Introduction}

The interactions between the fan and the OGV (Outlet Guide Vanes) occurring at blade passing frequencies are mainly responsible for aero-engines tonal noise emission at approach conditions. Modern turbofans are characterized by new design including composite fan blades with struts integrated to the OGV, pylons and internal bifurcations. The acoustic signature of these modern architectures in terms of SPL (Sound Pressure Level) spectra and directivities can be assessed thanks to dedicated tests on scaled turbofan models conducted by engine manufacturers. The objective of the present study is to provide the inlet radiation of a SNECMA engine model (named FAA) by means of CAA (Computational AeroAcoustics) methods. While the source generation process involving CFD simulations and in-duct sound power estimations are investigated in, ${ }^{1}$ we focus here on the ability of numerical propagation methods to recover the main far-field (radiated from the inlet) sound characteristics.

The FAA model is representative of new generation engines with struts integrated in the OGV. Because the stator is not axisymmetric, interaction modes are obtained by setting $V=1$ in the classical formula $m=n B \pm k V$ where $n$ and $k$ are integer and $B$ and $V$ are respectively the number of rotor blades and stator vanes. Consequently, all cut-on modes have to be considered. Several studies were dedicated to the prediction of fan noise radiation using CAA. However, past studies were limited to single interaction mode. Input data can be obtained from CFD as in ${ }^{2,3}$ or from measurements. ${ }^{4,5}$ Achunche et al. ${ }^{6}$ study the radiation from a test rig using FEM (Finite Element Method) considering several modes summed independently. The spinning modes amplitude is determined from experiment. For subsonic tonal noise, an equal power per mode assumption is used and gives a good agreement with measurements. A similar approach is proposed

\footnotetext{
${ }^{*}$ Research Engineer

${ }^{\dagger}$ Acoustic Engineer
} 
here. In-duct acoustic measurements issued from a recent engine test campaign are used as input data. The CAA is based on sAbrinA. VO $0^{2,7}$ Onera code solving the $3 \mathrm{D}$ Euler equations in a perturbation form, and considering a realistic inflow issued from a 2D-axi RANS computation using elsA Onera solver. ${ }^{8}$ The numerical results being limited to the near field, a Kirchhoff integral is used to assess the noise radiation in far-field. To limit the computational time and cost only the three first BPF (Blade Passage Frequency) are considered. They are noted respectively BPF1, BPF2 and BPF3. An important issue raised in the paper is the way of injecting the acoustic field in the propagation code, which is done here by using an equivalent-source approach initiated by Polacsek et al. ${ }^{9}$ and generalized recently by Gabard, ${ }^{10}$ adopting classical annular or cylndrical duct geometry and uniform mean flow assumptions. The equivalent-source approach permits to avoid the non-trivial difficulty of managing the incoming/outgoing waves when using standard BC (Boundary Conditions). A particular attention is devoted to the interference effects between the acoustic modes during propagation/radiation and numerical procedures are proposed in consequence. Those effects are clearly highlighted by comparing the experiment with the predictions obtained adding the modes in a coherent or non-coherent way. Beside these numerical predictions, simpler and faster analytical method using Wiener-Hopf formulation ${ }^{11}$ are also presented and discussed.

The first part of the paper is dedicated to the presentation of the test rig and the measured data. Secondly, the specific methodology employed in this paper are presented such the CAA source model and the far field extrapolation among others. The final part deals with comparisons between predictions and experimental data.

\section{Engine test rig and acoustic measurements}

A test campaign funded by a French Program on future engine demonstrators has been conducted by SNECMA in the RACE aeroacoustic test facility located near Saclay. ${ }^{12}$ A sketch of the engine test rig (inlet part view) is presented in Fig. 1(a). The microphone antenna, presented in Fig. 1(b), is located at $2.3 \mathrm{~m}$ from the duct inlet and can be rotated so that an acoustic scanning over almost half of a spherical surface can be assessed. In the present experiment, 17 microphones are used over 15 polar positions.

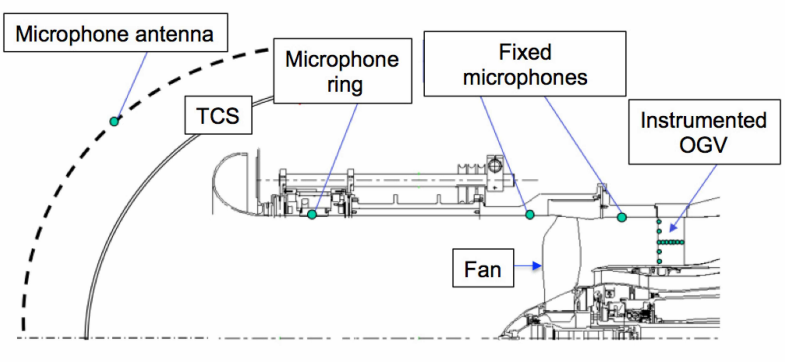

(a) Sketch of RACE test rig

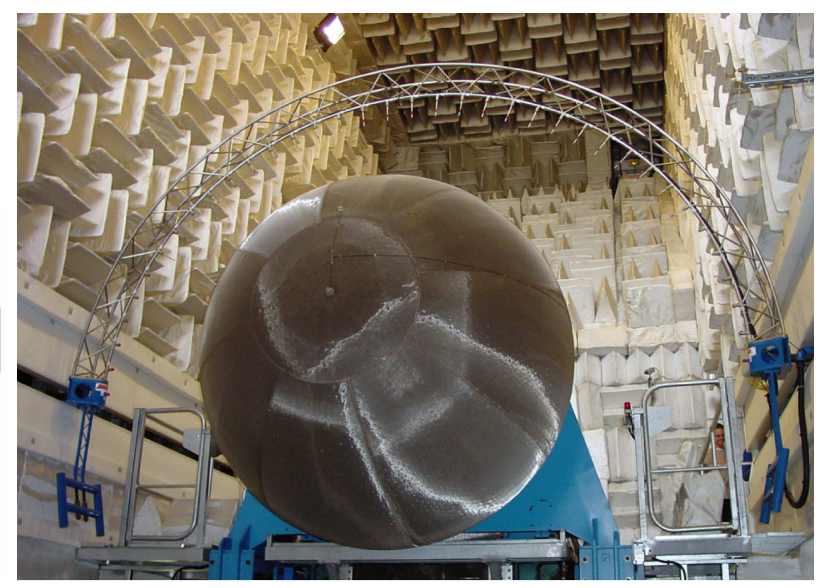

(b) Far field microphone antenna

Figure 1. Presentation of the RACE aero-acoustic test rig

The present configuration is a half-scale 18-bladed engine model at 50\% nominal speed (approach conditions). The engine is characterized by the presence of an heterogeneous OGV (non-identical 40 vanes including struts), giving rise to a cut-on BPF associated to all cut-on spinning modes due to the symmetry break. $^{1}$ A typical SPL spectrum measured by one microphone in the fan rig intake is presented in Fig. 2. One can note that the BPF is cut-on and that tonal noise is the dominant noise component. The angular mode spectra on the considered tones are shown in Figs. 3(a) to 3(c). They are obtained thanks to a wall-mounted rotating ring (one microphone fixed used as a reference and another rotating) placed in the fan rig intake. As already mentioned, dominant modes are not the ones expected from standard rotor-stator interactions with homogeneous OGV. Moreover, this measured noise is not only due to rotor-stator interactions but can also be eventually attribuated to inflow distortion. The cut-off range is shown by the black 
thick lines. Those limits do not appear clearly due to a low dynamic range and an increase of the noise level after the cut certainly due to aliasing effects. These angular mode spectra are used to calibrate the input data (acoustic duct modes amplitude) required for CAA and analytical methods. All the measured modes are no used. Table 1 presents the retained modes corresponding to a sound pressure level within 10 $\mathrm{dB}$ below the maximum on the three concerned BPF. Because of their high radiation power efficiency, the plane waves are also taken into account. Including radial modes, a total of 96 modes have to be considered. As no informations about radial modes are available from the measurements, each Fourier-Bessel mode amplitude is estimated by using radial mode shape functions at casing position, and assuming an equal energy distribution per mode. ${ }^{6,13}$ This point will be detailed in the Sec. III.

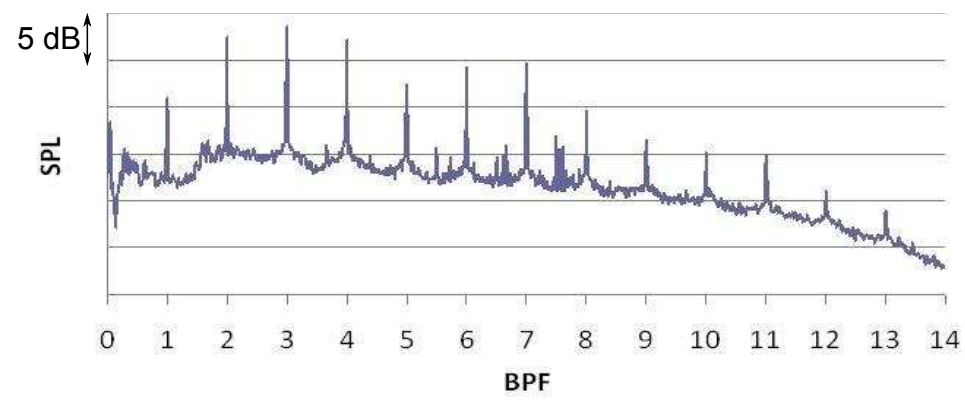

Figure 2. Noise spectrum at fan intake wall

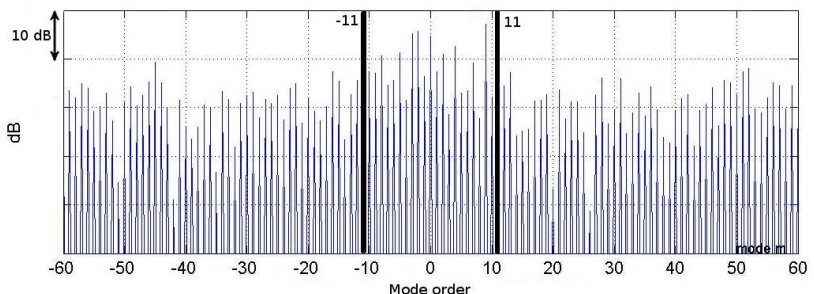

(a) Modal spectrum at BPF1

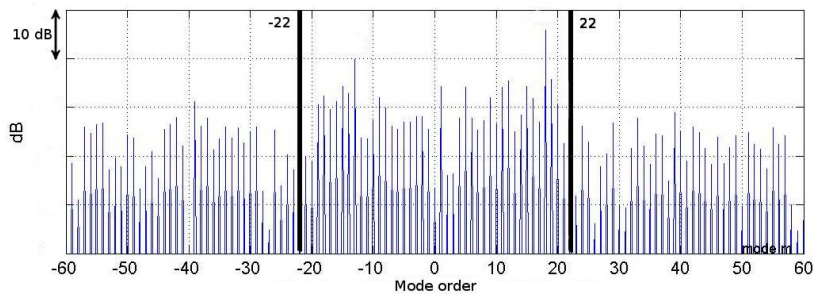

(b) Modal spectrum at BPF2

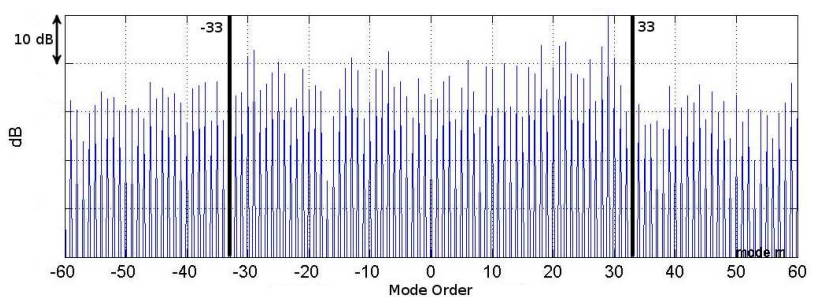

(c) Modal spectrum at BPF3

Figure 3. Angular mode spectra measured at intake wall 
Table 1. Selected propagating modes

\begin{tabular}{|c|c|c|c|c|c|c|c|c|c|c|c|c|c|c|c|c|c|}
\hline BPF 1 & -8 & -5 & -3 & -2 & 0 & 2 & 3 & 9 & & & & & & & & & \\
\hline BPF 2 & -19 & -18 & -16 & -15 & -14 & -13 & -9 & -8 & 0 & 1 & 5 & 9 & 11 & 12 & 15 & 18 & 19 \\
\hline BPF 3 & -30 & -29 & -25 & -13 & -7 & 0 & 6 & 12 & 18 & 20 & 21 & 26 & 28 & 29 & & & \\
\hline
\end{tabular}

\section{CAA and analytical models}

\section{III.A. Numerical procedure}

III.A.1. Euler solver

The code used in this study is the ONERA CAA code sAbrinA.V0. This code solves the non-linear Euler equations in perturbation form, with a sixth-order accurate finite-difference centered scheme in space, and a compact third-order Runge-Kutta algorithm for time marching. A tenth-order accurate symmetrical linear filter is applied to the flow variables at each time step to prevent occurrence of spurious wiggles. The code features multi-dimensional/multi-block structured grids. A slip condition is enforced at the solid body surface. In order to prevent numerical reflections from the boundaries of the computational domain, a high stretching is applied to the last cells of the grid combined with a reduction of the order of spatial scheme.

\section{III.A.2. Source model implementing}

Two ways for generating Fourier-Bessel modes are available in sAbrinA. V0. The first one allows to inject these modes in terms of usual BC (boundary condition). It consists in imposing the outgoing analytical solution in fictitious cells at each time step, and taking into account the phase dependency. The second one uses an equivalent-source model ${ }^{2,9}$ from which the modes are entered by means of suited distributed monopoles defined as source terms. The equivalent-source model has the advantage to properly manage the duct end reflection, whereas it is not fully achieved on a usual BC. ${ }^{9}$ In the BC approach, there is no damping zone upstream the injection plane and incoming waves amplitudes are imposed to zero. This abrupt transition may generate numerical reflections. Consequently, adequate damping zone can be added to deal with duct end reflection. Gabard ${ }^{10}$ recently addressed an improved formulation of previous equivalent-source model using mode shape (Bessel) functions and a continuous source distribution over a cross-section of the duct. This method, first presented by Gabard for a $2.5 \mathrm{D}$ formulation, is used in this paper in a $3 \mathrm{D}$ code. Considering isentropic harmonic disturbances (applied to density and pressure only), the equivalent-source term $q$ can be written as:

$$
q(r, \theta, t)=\sum_{m n} Q_{m n} \psi_{m n}(r) \cos (\omega t-m \theta)
$$

with

$$
Q_{m n}(\omega)=\frac{2 \Delta_{m n}}{\left(\omega-U_{0} k_{m n}\right) \hat{w}\left(k_{m n}\right)} A_{m n}(\omega)
$$

In Eqs. 1 and 2, $m$ and $n$ respectively denote the angular and radial mode order and $Q_{m n}$ is the source amplitude related to the mode shape function $\psi_{m n}$ (with normalization factor proposed by Rienstra ${ }^{14}$ ). $R$ is the outer duct radius, $k_{m n}$ is the axial wave number, $\Delta_{m n}$ is the non-dimensioned cut-off ratio, and $\hat{w}$ is the spatial Fourier transformed window function used in the CAA to control the compacity of the source. The window function is deduced from, ${ }^{9}$ where a bidimensionnal normalized gaussian function is used. In our case, the function is reduced to a monodimensional case (axial direction) given by Eq. 3. According to, ${ }^{9}$ $l \approx \Delta x$ where $\Delta x$ is the axial mesh discretization size. This leads to $\hat{w}\left(k_{m n}\right) \approx 1$ which prevents from the calculation of the spatial Fourier transform in Eq. 2.

$$
w(x)=\frac{1}{l} e^{\frac{-\pi x^{2}}{l^{2}}}
$$

This new formulation has been recently implemented in the sAbrinA. V0 code. A validation is proposed on the ideal case of an annular duct in uniform flow for which an analytical solution is available. The duct 
has a radius of $1 \mathrm{~m}$, a hub-to-tip ratio of 0.75 and the Mach number is equal to 0.45 . Figures $4(\mathrm{a})$ and 4 (b) present an instantaneous pressure distribution at outer duct wall for a plane wave and a mode $(17,2)$ at 1624 Hz. The source injection plane is located in $x=0$.

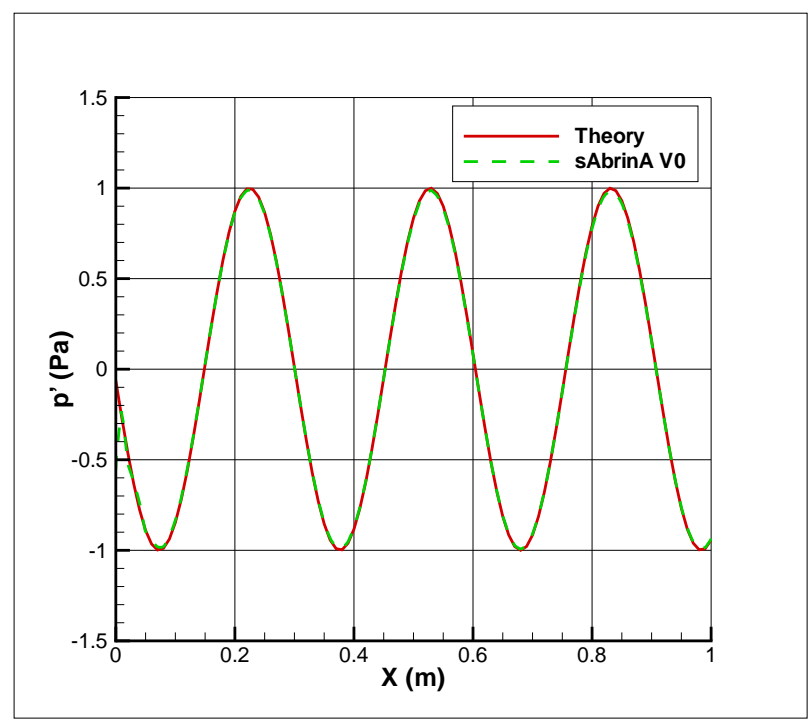

(a) Mode $(0,1)$

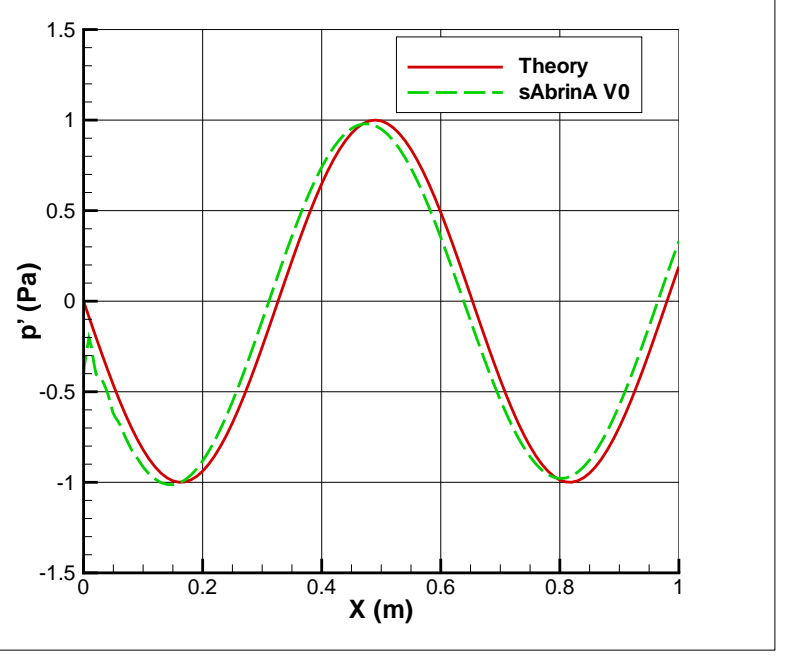

(b) Mode $(17,2)$

Figure 4. Instantaneous pressure distribution at the outer wall duct downstream of the source

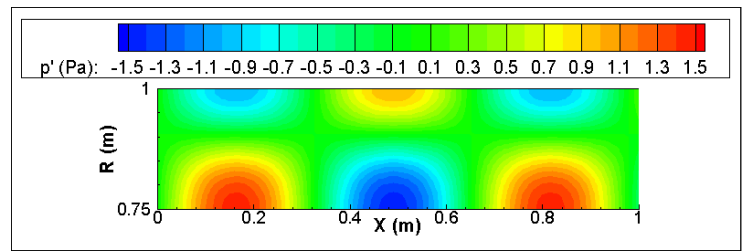

(a) Theory

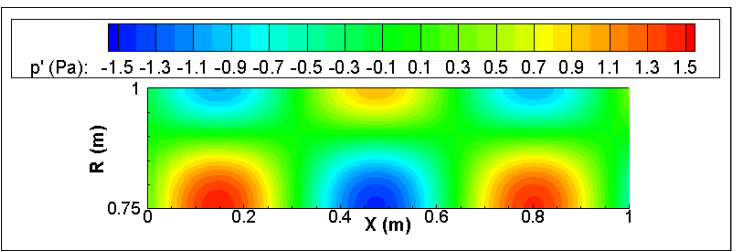

(b) $\operatorname{sAbrinA.VO}$

Figure 5. Instantaneous pressure distribution in a duct section downstream of the source generating a mode (17,2)

An very good agreement is obtained with a small delay for the mode $(17,2)$. As a complement, a 2-d view of the pressure field in a section of the duct is presented in Figs. 5(a) and 5(b). The shape of the mode is properly generated and propagated with the correct amplitude.

In a last test case, all the propagating modes related to the present engine model configuration (cf. Sec. II) are used. As already said in Sec. II, modal amplitudes in Eq. 1 are deduced from the angular mode spectra assuming an equal energy per mode, which can be expressed as:

$$
\left|A_{m n}(\omega)\right|^{2}=\frac{\left|P_{m}\right|^{2}}{\psi_{m n}(R)^{2} n_{\max }(\omega)}
$$

In Eq. $4, P_{m}$ is the angular mode amplitude (at angular frequency $\omega$ ) obtained experimentally, and $n_{\max }$ is the number of cut-on radial modes. These values are used for numerical and analytical predictions in this paper. The duct is assumed to be cylindrical with a radius of $0.4 \mathrm{~m}$. The flow is assumed to be uniform with a Mach number around 0.2. The acoustic propagation is made in the upstream direction. Snapshots of theoretical and numerical pressure perturbation in a transverse section of the inlet are presented in Figs. 6(a) and 6(b). Since numerous modes are injected, minor errors are summed so that small discrepancies are visible. However, the results are still in good agreement which validates the present multi-mode injection approach. 


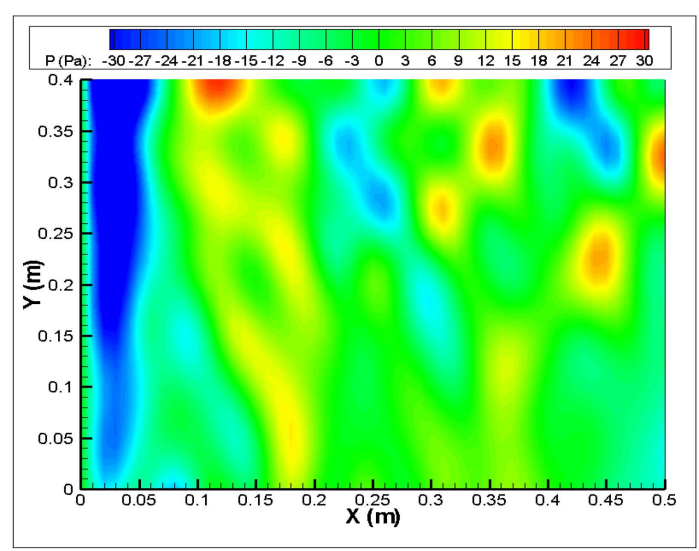

(a) Theory

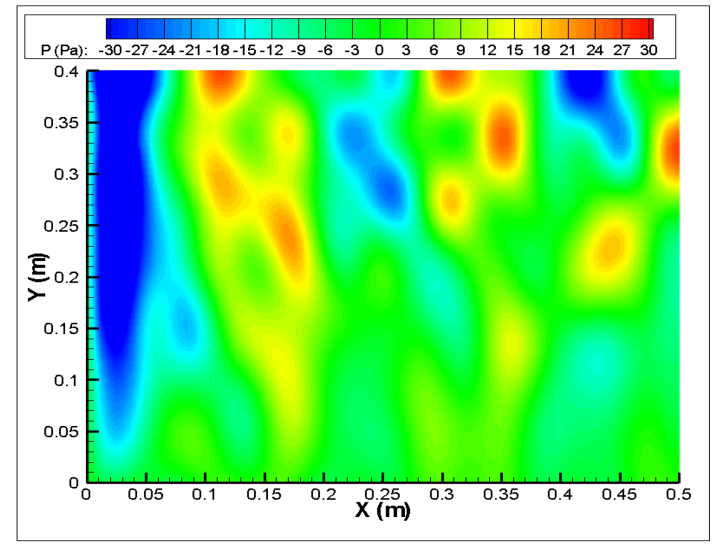

(b) sAbrinA.VO

Figure 6. Snapshots pressure maps in a longitudinal slice provided by theory (left) and CAA (right) for the FAA configuration approximated to a cylindrical duct

\section{III.A.3. Mesh and mean flow}

The mean flow used to convect the acoustic perturbation in the sAbrinA. V0 code is obtained from a RANS axisymmetric computation with the Onera CFD code els $A$. A centered Jameson scheme is used as well as a non-reflecting condition associated to a zero velocity flow in far field. A static pressure condition maintains the correct mass flow at the boundary inside the duct. This corresponds to a Mach number around 0.2. The resulting aerodynamic field is interpolated on the CAA mesh after being rotate in the azimuthal direction. Since the CAA domain in the inlet duct is larger than the CFD mesh, the aerodynamic data on the last cells are simply duplicated in the axial direction. A view of the axial Mach number can be observed in Fig. 7 after interpolation. Since it is a static test case, the velocity magnitude tends rapidly to zero and the flow aspiration effect is well visible thanks to the streamlines.

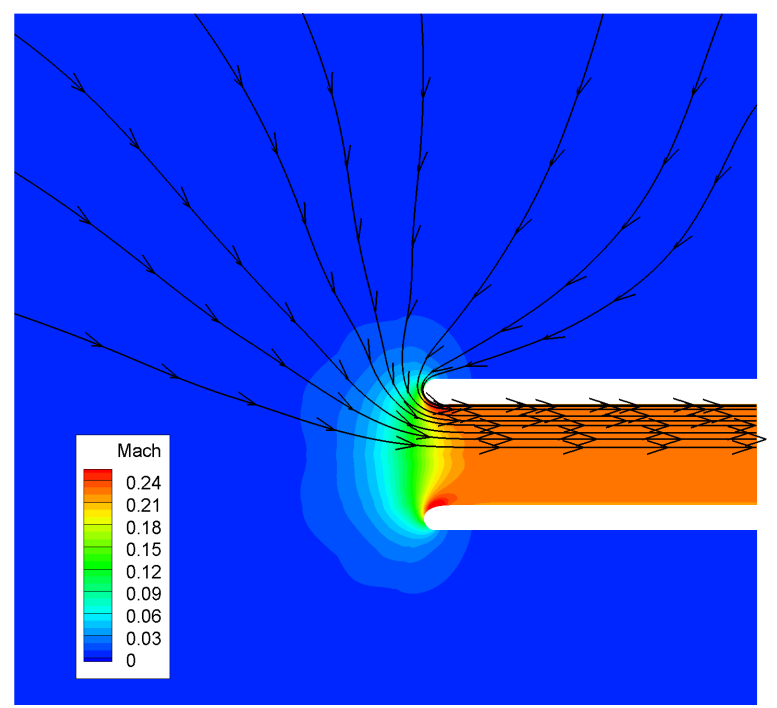

Figure 7. Interpolated axial Mach number map

A 22 million cells multi-block structured mesh has been constructed around the duct lips for the acoustic computation. An overall view of the mesh along two planes is presented in Fig. 8(a) highlighting the mesh stretching in far field to avoid numerical reflections. A close up of the mesh in the inlet area is presented in Fig. 8(b) with mean axial velocity contours. It can be observed that the center part of the mesh is no longer axisymmetric to avoid too small cell in the vicinity of the axis and the related too small time step to stay at low CFL number value $(C F L<1)$. Using this meshing strategy, the maximum CFL number is 
equal to 0.61 and one period of BPF1 is executed in 100 iterations. The grid was used for the last test case (cylindrical duct) of Sec. III.A.2.

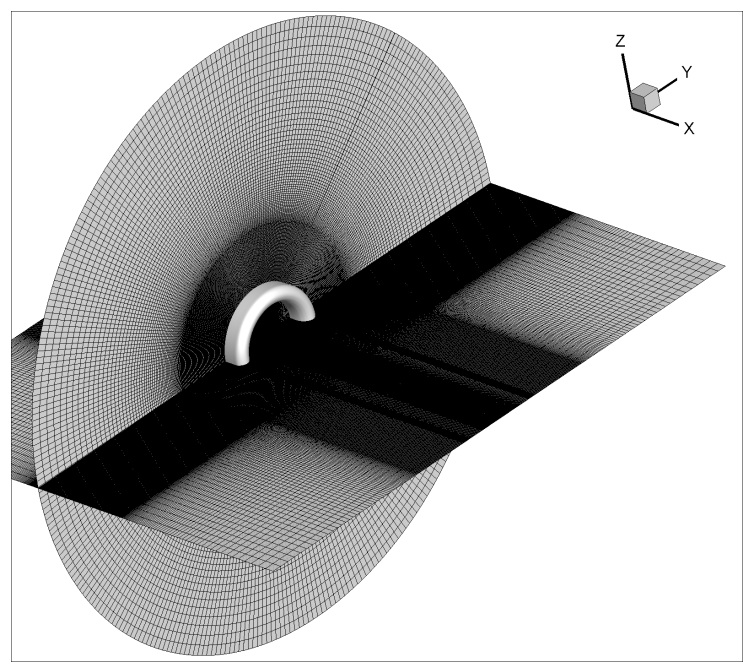

(a) Overview of the CAA mesh (X-Y and Y-Z planes)

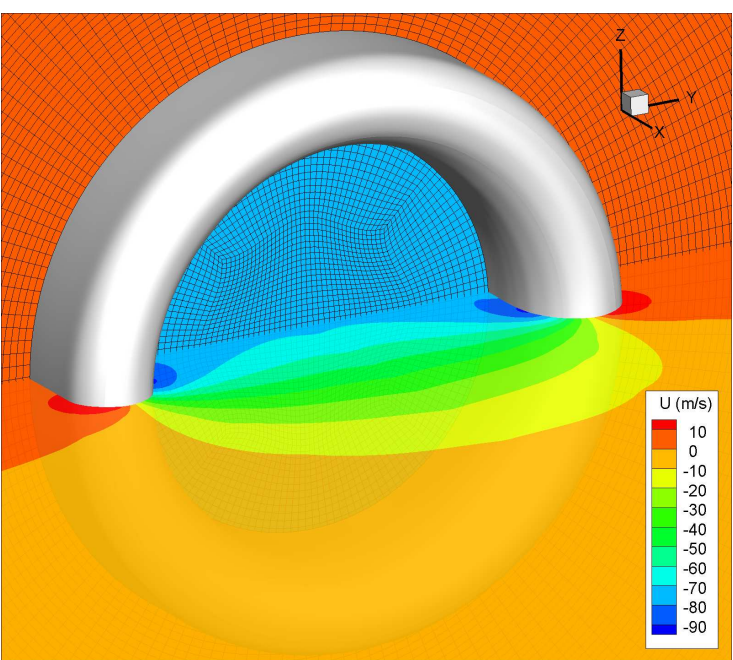

(b) Close view of the CAA mesh (one every two points) in the inlet with axial velocity contours

Figure 8. CAA mesh illustrations

\section{III.A.4. Far field extrapolation}

To reduce the computational cost, the CAA mesh does not extend to the microphones location in far field. Consequently, an extrapolation method has to be used. Since perturbations are purely acoustic, a simple Kirchhoff integral (as defined $\mathrm{in}^{2}$ ) is used instead of a more complicated Ffowcs-Williams and Hawkings formulations. This is performed thanks to the ONERA code $M I A$ which solves several integral methods in the frequency domain. One can note that although we used a time-domain CAA code, the used of a frequency domain method is justified since only three frequencies are of interest. Three different integration surfaces are considered to check the consistency of the extrapolation method. Those surfaces are presented in Fig.9. The surfaces are placed sufficiently far from the inlet so that the flow velocity is uniform and close to zero. Consequently, the fluid is supposed to be at rest in the Kirchhoff integral.

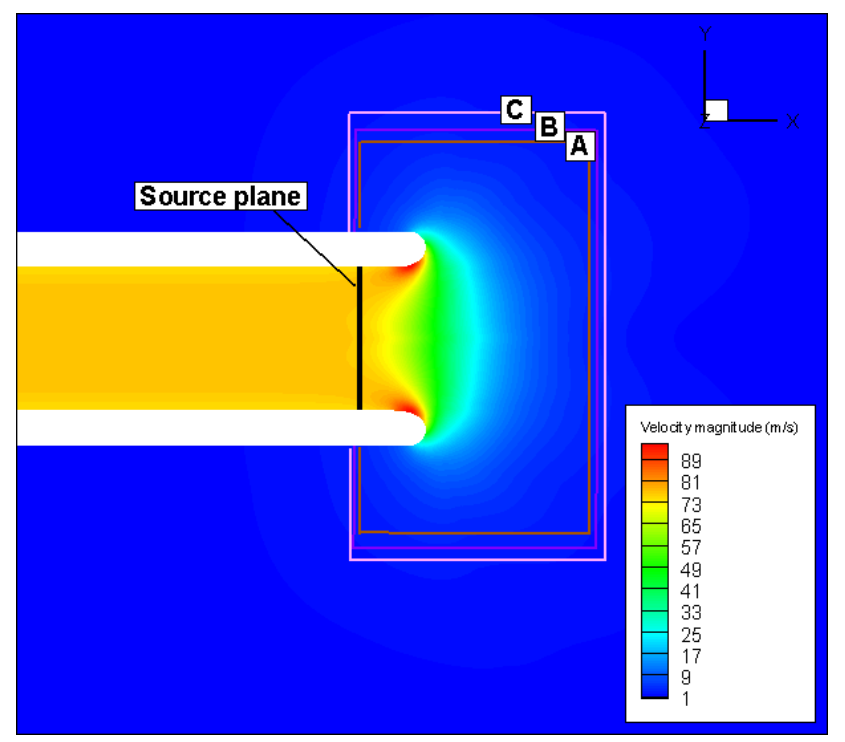

Figure 9. Integration surfaces used for the Kirchhoff integral on a map of velocity magnitude

Figures 10(a) and 10(b) proved the stability of resolution of the Kirchhoff in terms of dissipation, mean 
flow effect and encompassing of the source. For the three surfaces, the directivity at $2.3 \mathrm{~m}$ is plotted for BPF1 and BPF3 (i-e the most critical cases). 96 modes previously defined (cf. Sec. III.A.2) are injected with a zero phase angle at the same axial location than the microphone ring used for the modal analysis as represented in Fig. 9. The surface noted $\mathrm{A}$ is the closest and the surface $\mathrm{C}$ is the farthest. $\theta=0$ corresponds to the engine axis. The results are almost identical for the three surfaces on BPF1. On BPF3, the highest discrepancy is equal to $1.9 \mathrm{~dB}$ in the last angle. Except for this angle, the three surfaces provide identical results. Thus, the farthest surface is retained.

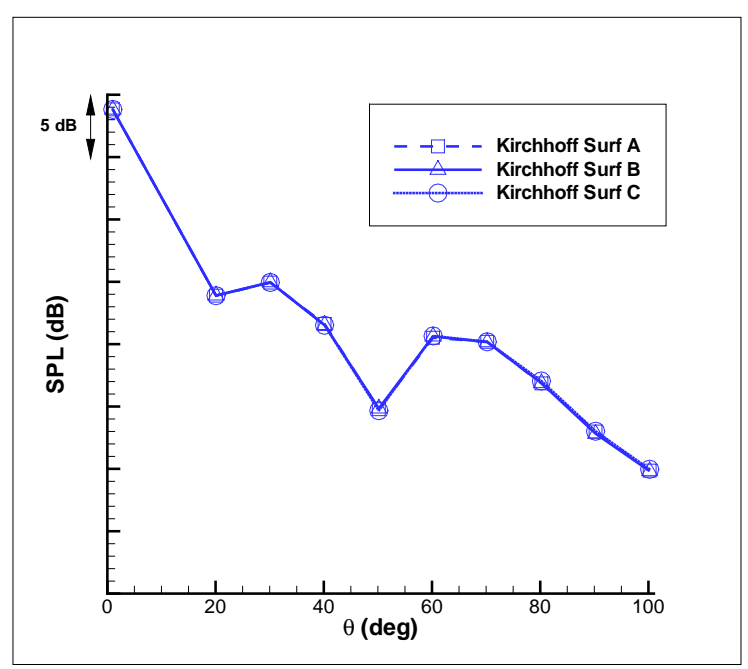

(a) BPF1

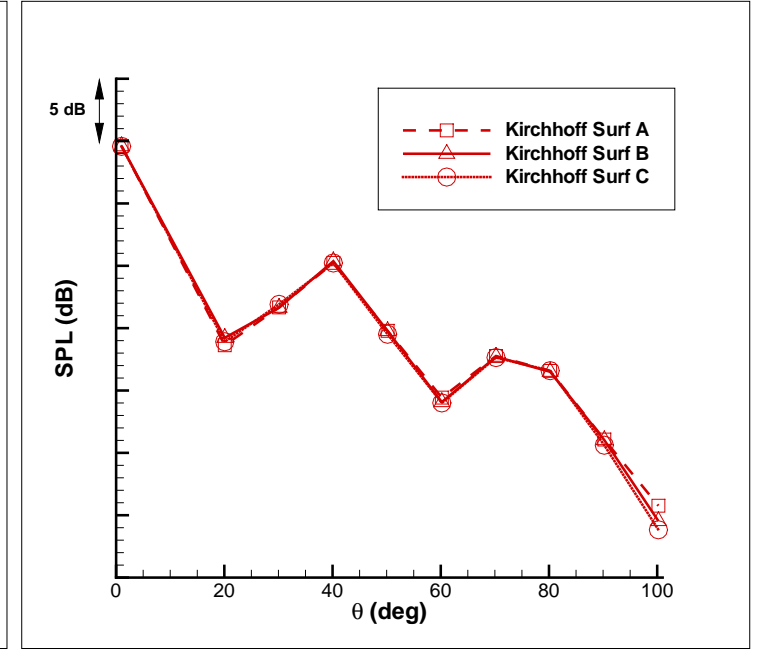

(b) BPF3

Figure 10. Noise directivities for three different Kirchhoff surfaces on BPF1 and BPF3

Another validation of the Kirchhoff method is proposed in Fig. 11. RMS (Root Mean Square) contours of pressure provided by the CAA code are display. Iso-value are represented by discontinuous lines. The solution issued from the coupling with the Kirchhoff integral is overplotted inside the white box with continuous lines. This highlights the continuity of the acoustic patterns across the Kirchhoff surface (rectangular pink box). Farther from the Kirchhoff surface, continuity is lost due to a degradation of the CAA solution in the stretched mesh areas.

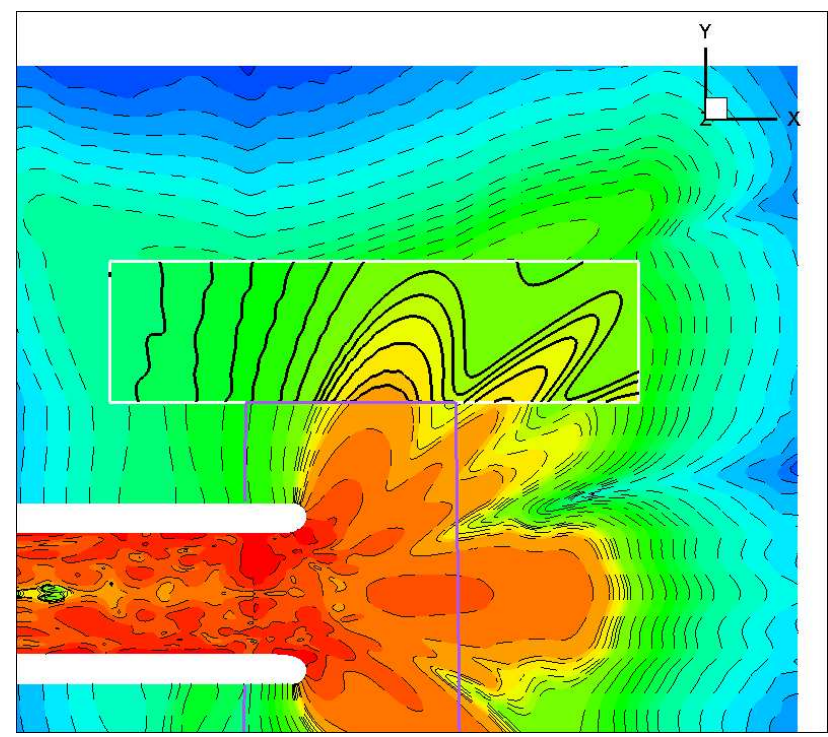

Figure 11. Iso-contour of RMS pressure directly provided by $\operatorname{sAbrinA.VO}$ (discontinuous lines) and after extrapolation by $M I A$ (continuous lines) 


\section{III.B. Analytical predictions}

As a complement to the numerical study, an analytical approach is also investigated. This method is justified by the relatively simple shape of the lips and a mean flow without large discontinuity such as shear layer. The method, developed by Lordi and Homicz, ${ }^{11}$ is based on a Wiener-Hopf technique. The solution is valid for a cylindrical duct with zero thickness. A uniform flow assumption is obtained via a Prandtl-Glauert transformation. Contrary to the Kirchhoff method used to extrapolate the CAA computation in far field for which virtual sources are taken in a region where the fluid is almost at rest, the Mach number considered here is equal to the in-duct mean value to insure a necessary continuity between the in-duct and free-field regions. The mathematical expression of the radiated pressure $p(\vec{X}, t)$ is given by:

$$
p(\vec{X}, t)=\sum_{m=-\infty}^{\infty} \sum_{n=0}^{\infty} A_{m n} D_{m n} \frac{e^{i\left(\omega t-k D-k_{m n} x_{v}\right)}}{D}
$$

In Eq. $5, x_{v}$ is the distance between the source plane and the inlet duct end, $k_{m n}$ and $k$ are respectively, axial wave number of the mode $(m, n)$ and the acoustic wave number. $D$ is the distance between the center of the outlet plane and the observer. Finally, $D_{m n}$ is a directivity factor detailed in. ${ }^{11}$

\section{III.C. Mode coherence canceling}

A crucial point addressed in this section is the effect of mode coherence responsible for cancellation patterns (due to destructive interferences between modes) and giving rise to a non-axisymmetric field. Indeed, if several modes are generated at the same time, the contribution of each mode is added in a coherent way in the numerical process. Analytical and numerical predictions often suppose uncorrelated modes. ${ }^{5,6,13}$ This hypothesis allows to get rid of interference effects that usually disappear during experimental test due to ensemble average realized over a long period of time. Slight variations in test conditions (rotor speed for example) induce change in the phase of the acoustic sources resulting in a decorrelation. The simplest method to obtain uncorrelated modes is to perform one simulation per mode and sum the quadratic pressure value of each individual computation. ${ }^{15}$ Obviously, this kind of approach is realistic only if very few modes are considered.

Another technique ${ }^{16}$ to cancel the correlation between modes (at BPF tones here) is to add a random phase per mode and to perform a quadratic averaging over $N_{k}$ independent runs. This technique applied to tone noise simulations is unpractical because too many realizations are required to make the statistical errors acceptable.

A last technique adopted here consists in injecting only all angular modes with same radial mode order, and to perform $n_{\max }$ runs. Introducing spherical coordinates $(r, \theta, \varphi)$, a non-coherent mode solution is then simply obtained by performing an azimuthal average:

$$
|P(r, \theta)|^{2}=\frac{1}{2 \pi} \int_{0}^{2 \pi} \sum_{k=1}^{n_{\max }}\left|P_{k}(r, \theta, \varphi)\right|^{2} d \varphi
$$

Since $n_{\max }$ practically remains rather low $\left(n_{\max }=5\right.$ on BPF3 in our case), this last approach is quite suitable for realistic engine model applications dealing with tonal noise.

\section{Acoustic predictions and comparisons with experiment}

The sound fields obtained using predicting methods described in Sec. III are discussed now, by comparison with measurements.

Figure 12 shows the analytically computed levels for the considered tones compared to the experimental results measured in the fan intake rig at the wall.

Analytical results are obtained using an uncorrelated mode hypothesis. Results are satisfactory on the two first BPF with a discrepancy between 1 and $1.5 \mathrm{~dB}$. However, on the last considered BPF, analytical and experimental results differ by $3.5 \mathrm{~dB}$. The energy distribution between radial mode is a first source of error. Also, the uncorrelated hypothesis might not be completely fulfilled in this case.

Figures 13, 15 and 17 present the noise directivities on the hemisphere in far-field obtained analytically, numerically and experimentally for the three BPF using a coherent mode assumption. Practically, each 


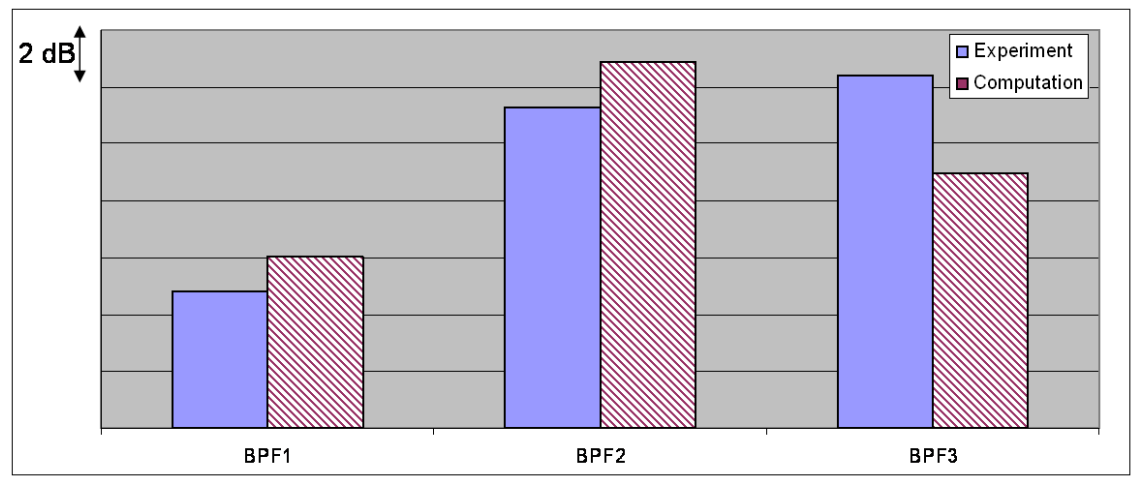

Figure 12. Tones level comparison at the outer wall duct between experimental and analytical results

modes are injected with a phase arbitrary set to zero. The measurements correspond to raw data. Experimental directivities are clearly not axisymmetric. Consequently, some interference effects between modes are suspected. In particular, a standing wave ratio in the angular direction due to spinning modes of same order and opposite sign. Installations effects could also be involved. Relatives noise levels are in good agreements but significant discrepancies are obtained on the azimuthal direction even between theoretical and numerical results. Instead of a zero phase angle, each modes can be injected with his specific phase provided by the experimental modal analysis. Using this approach do not induce improvements and similar tendencies are obtained with a different energy distribution on the azimuthal direction.

Figures 14, 16 and 18 present the noise directivities on the hemisphere in far-field obtained analytically, numerically and experimentally for three considered BPF using an incoherent mode assumption. The theoretical result is obtained by summing independently the propagating modes. The numerical result is achieved by using the technique described in section III.C. Concerning the measurement, a "pseudo" incoherent directivity is obtained by an azimuthal average. A more precise comparison is presented in Fig. 19 showing noise level as a function of the polar angle. A relatively good agreement is observed apart from prediction in the axis and at $90^{\circ}$. Also, largest discrepancies are visible on BPF1 while the better result is obtained on BPF2. Overall Sound Pressure Level (OASPL) on BPF1 to 3 is also represented. OASPL is clearly dominated by the BPF1 close to the axis due to a strong plane wave. For higher angles, BPF2 is the main contributor. The two predicting approaches (numerical and analytical) provide results which are reasonably closed from each other considering the hypothesis made in the theoretical methodology (uniform flow, thin geometry). However, numerical predictions are in better agreement with measurements. Even if differences can be up to $6 \mathrm{~dB}$ at $\theta=90^{\circ}$, a very good agreement is provided between $20^{\circ}$ and $70^{\circ}$ with a maximum discrepancy of $0.7 \mathrm{~dB}$ on OASPL.

\section{Conclusion}

The goal of this study was to realize predictions of tonal noise generated by a SNECMA turbofan mock up with a heterogeneous stator and radiated from the inlet using as input a modal decomposition measured in the inlet duct wall. A numerical approach based on the CAA code sAbrinA.VO with a source term recently implemented has been used as well as an analytical methodology using a Wiener-Hopf technique and uniform flow assumption. The mean flow in the inlet duct is provided by a RANS axisymmetrical computation. Analysis presented in the paper allow us to highlight the following facts:

- Comparisons between theoretical and numerical predictions confirm the practical interest of using simplified method even if noticeable improvement of the results can be provided by more complex and time consuming methods like CAA.

- The accuracy of the new source term in the CAA code $s$ AbrinA. VO has been checked and successfully applied on an industrial configuration.

- Although directivities from raw experimental data exhibit significant variations of noise level in the azimuthal direction, the hypothesis of incoherent modes inducing axisymmetric directivities allow to 


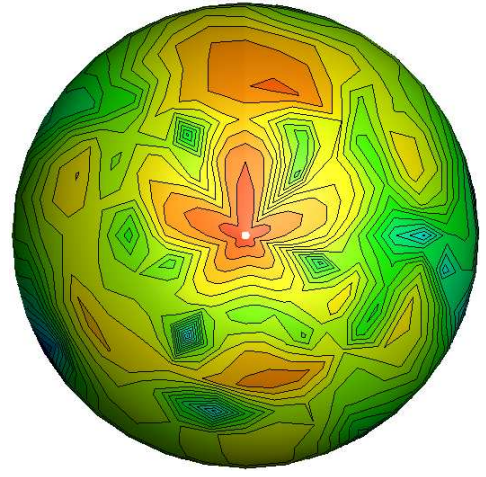

(a) Theory

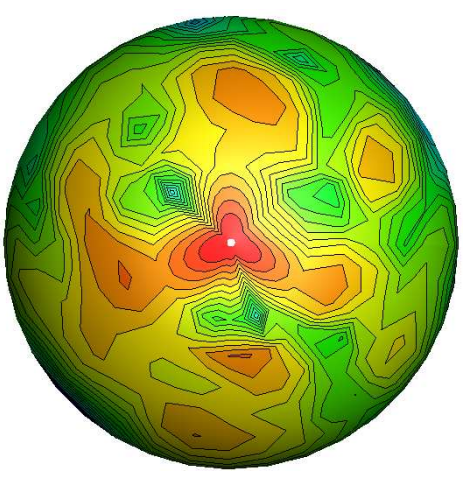

(b) CAA+Kirchhoff

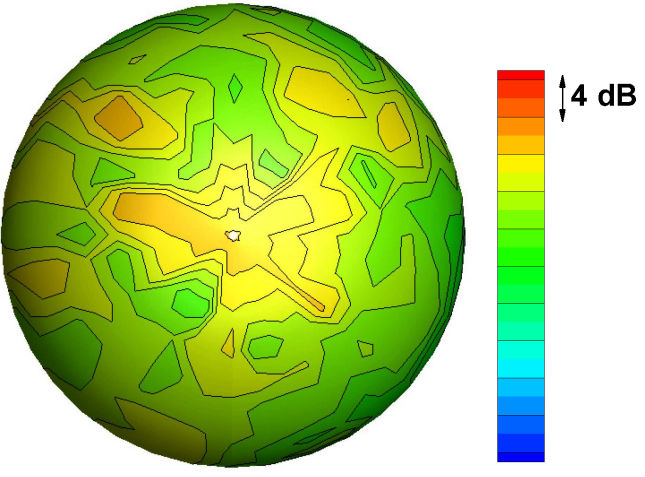

(c) Measurements

Figure 13. Comparisons of SPL (dB) maps on BPF1 issued from experiment and calculations using a coherent mode assumptions

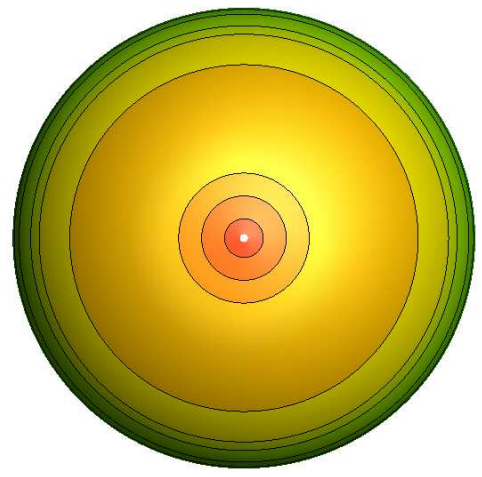

(a) Theory

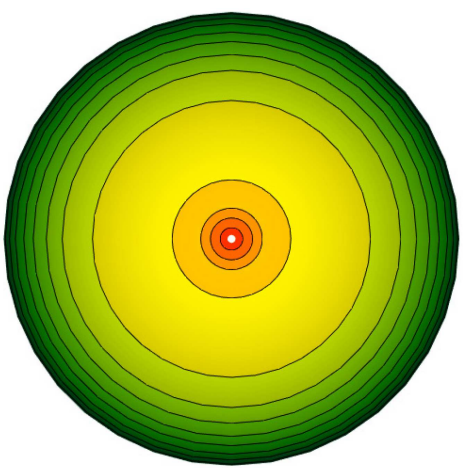

(b) CAA+Kirchhoff

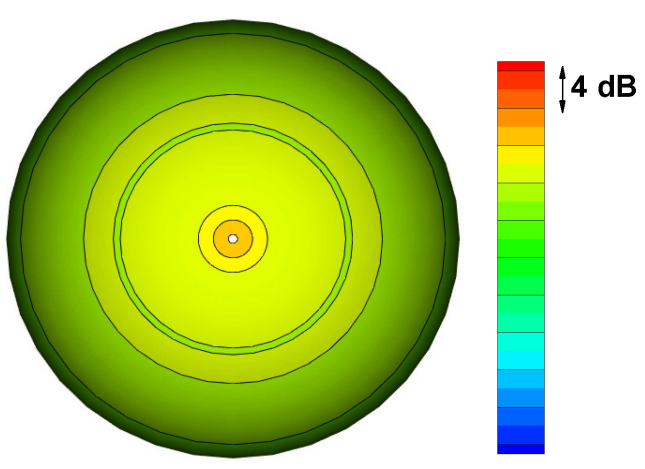

(c) Measurements

Figure 14. Comparisons of SPL (dB) maps on BPF1 issued from experiment and calculations using a incoherent mode assumptions

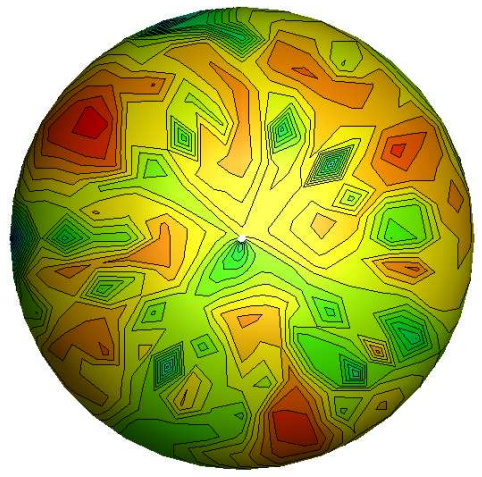

(a) Theory

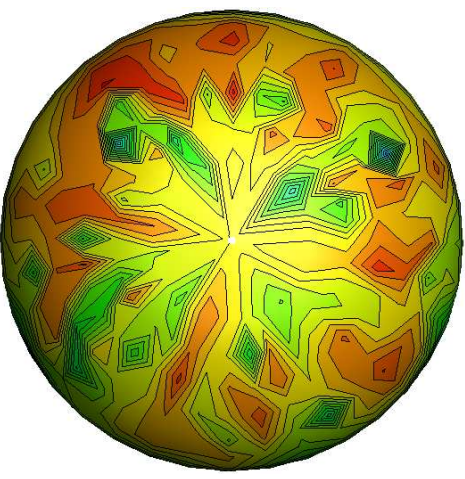

(b) CAA+Kirchhoff

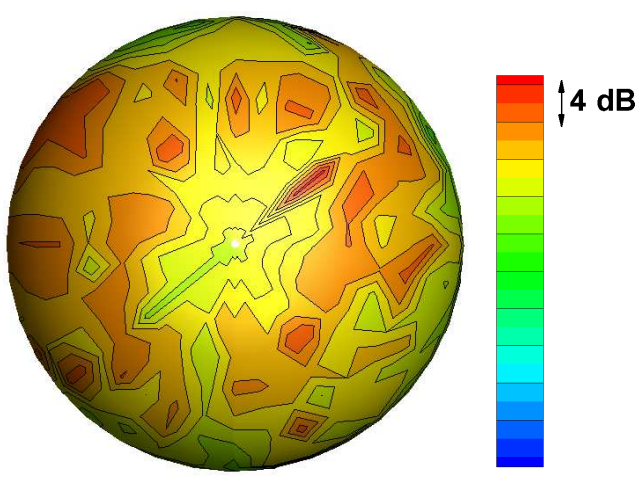

(c) Measurements

Figure 15. Comparisons of SPL (dB) maps on BPF2 issued from experiment and calculations using a coherent mode assumptions 


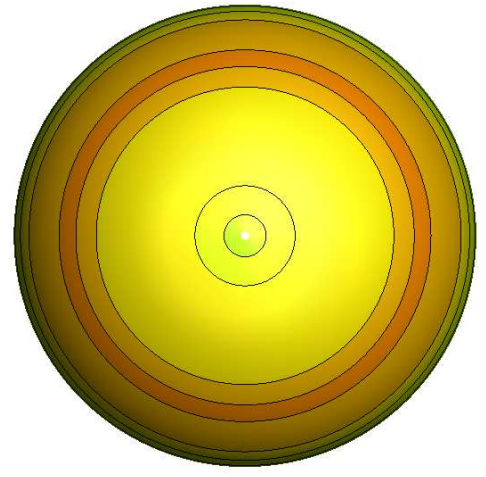

(a) Theory

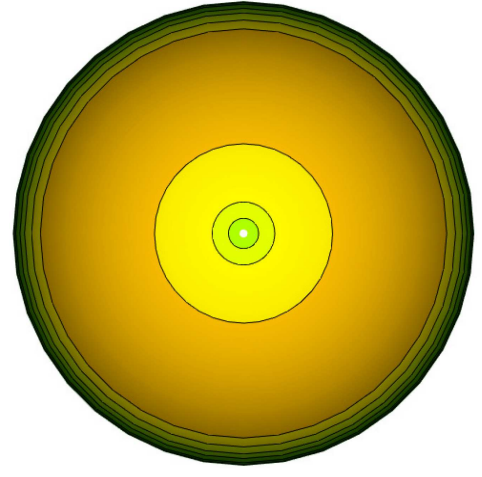

(b) $\mathrm{CAA}+$ Kirchhoff

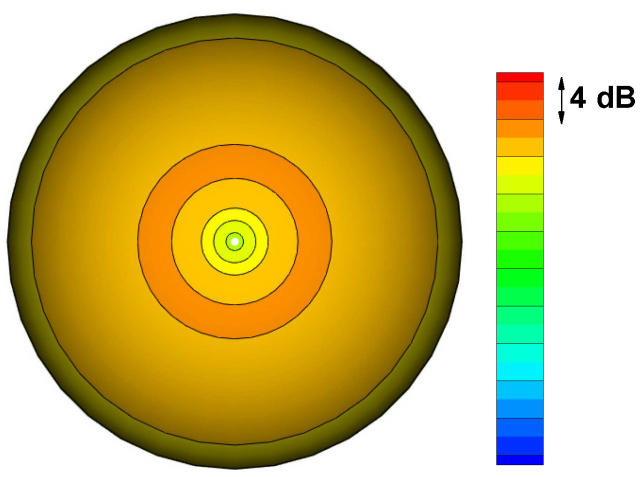

(c) Measurements

Figure 16. Comparisons of SPL (dB) maps on BPF2 issued from experiment and calculations using a incoherent mode assumptions

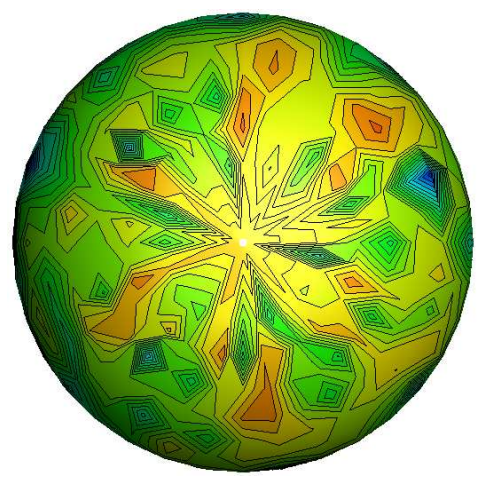

(a) Theory

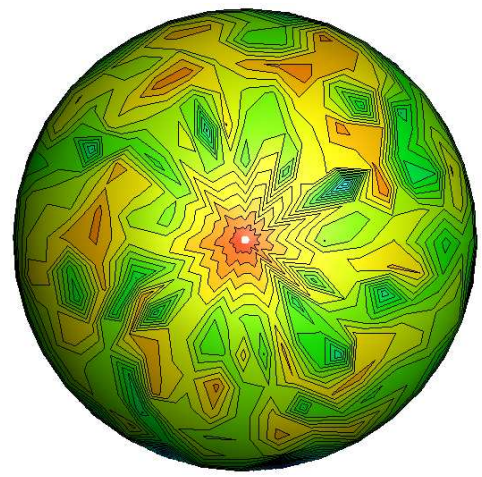

(b) CAA+Kirchhoff

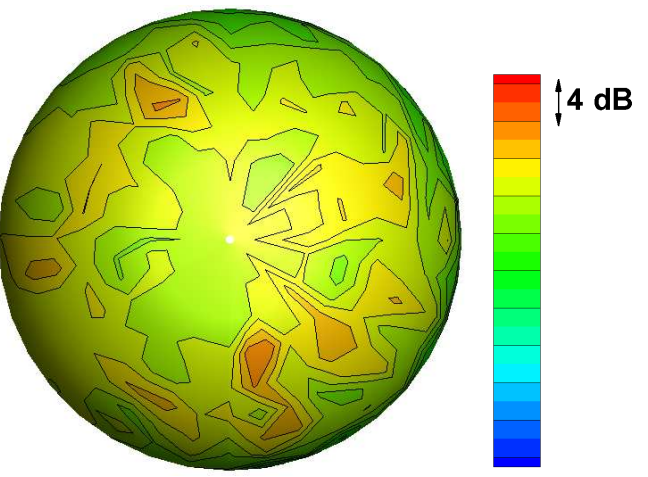

(c) Measurements

Figure 17. Comparisons of SPL (dB) maps on BPF3 issued from experiment and calculations using a coherent mode assumptions

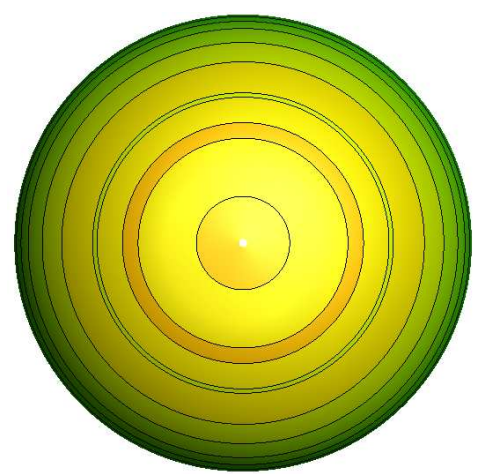

(a) Theory

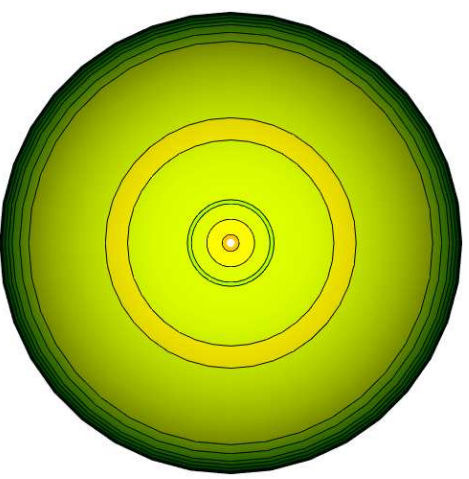

(b) CAA+Kirchhoff

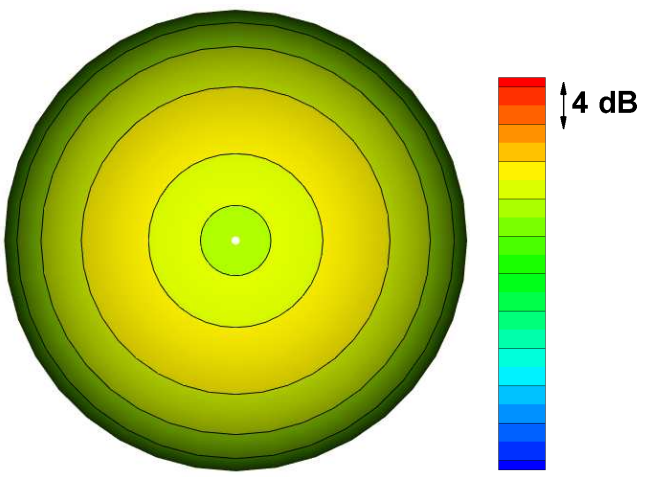

(c) Measurements

Figure 18. Comparisons of SPL (dB) maps on BPF3 issued from experiment and calculations using a incoherent mode assumptions 


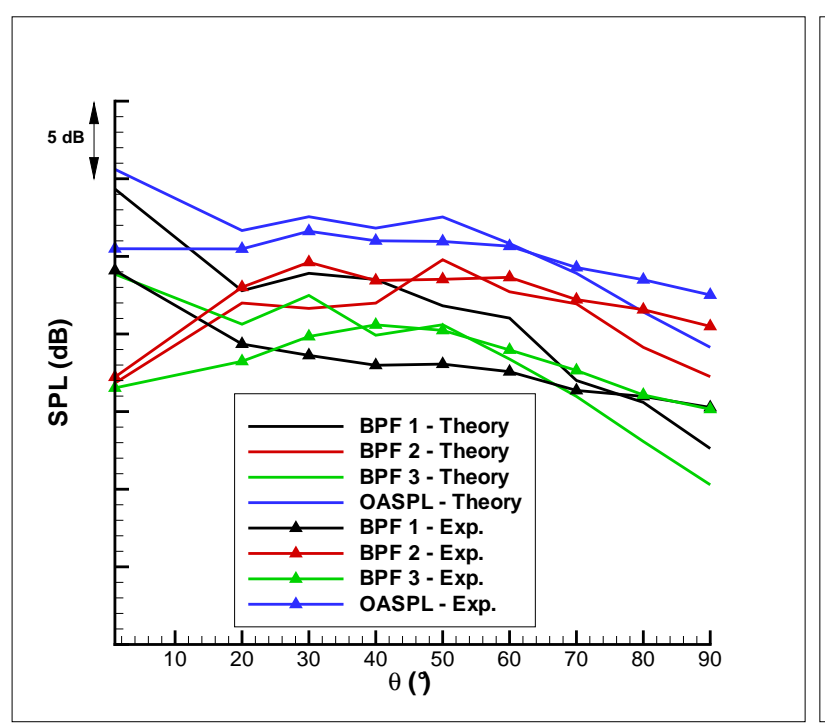

(a) Theory and Measurements

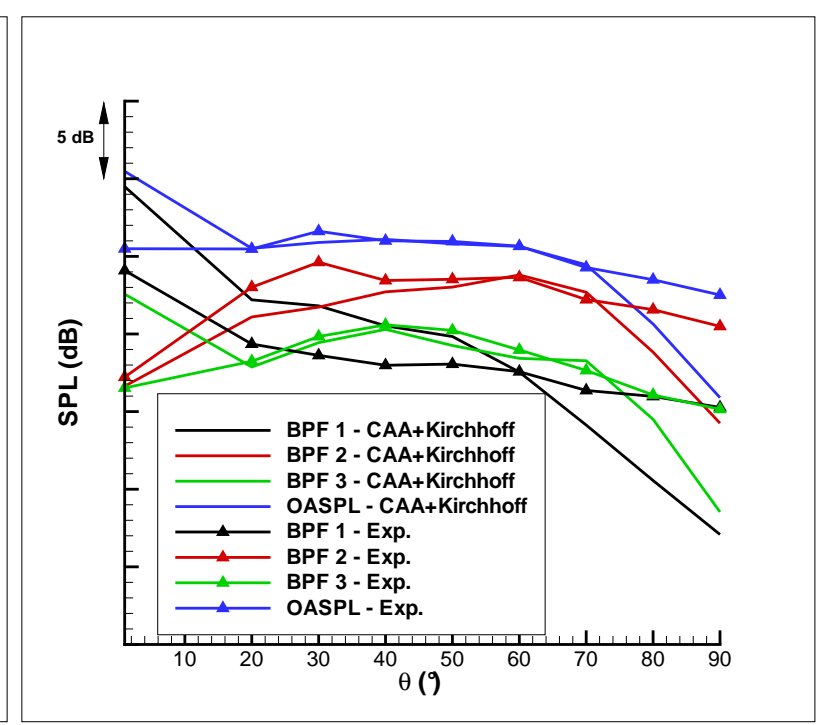

(b) CAA and Measurements

Figure 19. SPL and OASPL axi-directivities

compare reasonably well with measured data averaged azimuthally. Especially, for polar angles between $20^{\circ}$ and $70^{\circ}$, a very good agreement is obtained with a maximum discrepancy of $0.7 \mathrm{~dB}$ on OASPL.

- The influence of correlation effect between modes seems to be not negligible on this case. This fact is maybe related to the involvement of numerous modes. In particular, a standing wave ratio in the angular direction due to spinning modes of same order and opposite sign can be suspected.

- Best possibilities of improvement come from a better source definition. For example, the use of in-duct SPL can be used as in ${ }^{6}$ to calibrate more accurately the modal amplitude and the distribution of energy on radial modes.

\section{References}

${ }^{1}$ Bonneau, V., Polacsek, C., and Barrier, R., "Prediction of Interaction Noise Generated by a Modern Turbofan with Heterogeneous OGV and Internal Bifurcations," Proceedings of the Internoise 2012 Conference, Innsbruck, Austria, 2012.

${ }^{2}$ Polacsek, C., Burguburu, S., Redonnet, S., and Terracol., M., "Numerical Simulation of Fan Interaction Noise Using a Hybrid Approach," AIAA Journal, Vol. 44 (6), 2006, pp. 1188-1196.

${ }^{3}$ Fukushima, Y., Misaka, T., and Obayashi, S., "CFD-CAA Coupled Computation of Fan Noise Propagation From Engine Nacelle Based on Cartesian Mesh Method," Proceedings of the 19th AIAA/CEAS Aeroacoustics Conference, 2013, Berlin, Germany, No. AIAA 2013-2020, 2013.

${ }^{4}$ Sugimoto, R., Murray, P., McAlpine, A., and Astley, R. J., "Prediction of In-duct and Near-field Noise for a Fan Rig Intake," Proceedings of the 19th AIAA/CEAS Aeroacoustics Conference, Berlin, Germany, No. AIAA 2013-2022, 2013.

${ }^{5}$ Miller, S. A. E., Morris, P. J., and Zhao, Y., "Prediction of Fan Exhaust Noise Propagation," Proceedings of the 15th AIAA/CEAS Aeroacoustics Conference, Miami, FL, USA, No. AIAA 2009-3145, 2009.

${ }^{6}$ Achunche, I., Astley, J., Sugimoto, R., and A.Kempton, "Prediction of Forward Fan Noise Propagation and Radiation from Intakes," Proceedings of the 15th AIAA/CEAS Aeroacoustics Conference, Miami, FL, USA, No. AIAA 2009-3239, 2009.

${ }^{7}$ Redonnet, S., Manoha, E., and Sagaut, P., "Numerical Simulation of Propagation of Small Perturbations Interacting with Flows and Solid Bodies," Proceedings of the 7th AIAA/CEAS Aeroacoustics Conference, No. AIAA 2001-222, 2001.

${ }^{8}$ Cambier, L. and Veuillot, J., "Status of the elsA CFD Software for Flow Simulation and Multidisciplinary Applications," Proceedings of the 46th AIAA Aerospace Sciences Meeting and Exhibit, Reno, USA, 2008.

${ }^{9}$ Polacsek, C., Desquesnes, G., and Reboul, G., "An Equivalent-Source Model for Simulating Noise Generation in Turbofan Engines," Journal of Sound and Vibration, Vol. 323, 2009, pp. 697-717.

${ }^{10}$ Gabard, G., "Stochastic Sources of Broadband Noise for Time-Domain Simulations of Duct Acoustics," Proceedings of the 18th AIAA/CEAS Aeroacoustics Conference, Colorado Springs, CO, USA, 2012.

${ }^{11}$ Homicz, G. and Lordi, J., "A Note on the Radiative Directivity Patterns of Duct Acoustic Modes," Journal of Sound and Vibration, Vol. 41 (3), 1975, pp. 283-290.

${ }^{12}$ Genoulaz, N., Julliard, J., Lozachmeur, C., and Caujolle, C., "RACE Aero Acoustic Test Facility: Fan Forward and Rearward 3D Noise Measurements," 12th AIAA/CEAS Aeroacoustics Conference, Cambridge, Massachusetts, USA, No. AIAA 2006-2551, 2006 
${ }^{13}$ Joseph, P., Morfey, C., and Lowis, C., "Multi-mode Sound Transmission in Ducts with Flow," Journal of Sound and Vibration, Vol. 264, 2003, pp. 523-544.

${ }^{14}$ Rienstra, S. W., "Acoustic Radiation from a Semi-infinite Annular Duct in a Uniform Subsonic Mean Flow," Journal of Sound and Vibration, Vol. 94 (2), 1984, pp. 267-288.

${ }^{15}$ Manera, J., Leneveu, R., Caro, S., and J.Mardjono, "Broadband Turbomachinery Noise: Exhaust Noise Computations with Actran/TM and Actran/DGM," Proceedings of the 15th AIAA/CEAS Aeroacoustics Conference, Miami, FL, USA, No. AIAA 2009-3292, 2009.

${ }^{16}$ Reboul, G. and Polacsek, C., "Towards Numerical Simulation of Fan Broadband Noise Aft Radiation from Aero-engines," AIAA Journal, Vol. 48(9), 2010, pp. 2038-2048. 



\section{ONERA}

BP 72 - 29 avenue de la Division Leclerc - 92322 CHATILLON CEDEX - Tél. : +33 146734040 - Fax : +33 146734141

w w w. onera.f r 